\title{
THE TREATMENT OF WOUNDS THROUGH THE AGES
}

\author{
by \\ SIR ZAGHARY GOPE, \\ B.A., M.D., M.S., F.R.C.S.
}

THE treatment of wounds is the oldest surgical problem. Mankind has always been prone to accidental cuts and bruises, and mortal strife has led to the infliction of innumerable wounds in all ages of which we have record. The methods of treatment have varied from age to age, and from time to time there have been vigorous conflicts of opinion as to what was the best procedure to adopt. During the past twenty years a greater degree of agreement has been reached.

In one of the earliest medical records which have come down to us-the Edwin Smith papyrus-the regular treatment for an open wound was to apply a piece of fresh meat. (It is rather remarkable that even at the present time a popular remedy for severe bruises is of a similar nature.) After a few days it was recommended that an ointment composed of honey and grease should be applied to the wound. But the ancient Egyptian practitioner was very wary. For a severe wound of the arm which communicated with a fracture of the humerus he was advised not to undertake treatment.

In the Iliad we are given very few details as to the methods of treatment of wounds sustained in the course of the Trojan war. We can, however, gather the fact that the surgeon at this time (about rooo B.c.) was held in high esteem, that he either drew out or cut out arrows and other weapons which had penetrated the flesh, and either washed the wound or sucked it and thereafter applied a soothing dressing. Patroclos treated Euryalus by laying his patient on a bed of hides, washing the wound with warm water, and dropping into the wound a powdered root which stanched the bleeding and soothed the pain. The only other fact about the root which we are told is that it was a bitter substance.

Five hundred years later lived Hippocrates, the leader of an established profession of medicine and surgery. It is important to know something of what Hippocrates recommended for wounds, for, with slight variations, the treatment he advised persisted for over two thousand years. He insisted on general rest for the patient and immobility of the affected part. He advised moderate bleeding, either by allowing blood to flow from the wound or by opening a vein. $\mathrm{He}$ recommended purgation with the view of avoiding inflammation. He was in favour of a moderate diet and the drinking of water, not wine. In some cases he left the wound alone without local application or any bandage. Generally, however, the wound was dried with a sponge, then a piece of clean dry linen was applied and over that the medicament. Wine or vinegar were common I63 


\section{Sir Zachary Cope}

applications. Oily substances were not in favour. Many details which we should have liked to know are omitted. We are not told how the edges of the wound were brought together, though the absence of mention of sutures makes it likely that bandaging was thought sufficient.

Hippocrates regarded suppuration as the usual accompaniment of the healing of wounds, and he recommended the application of non-irritating medicaments to hasten the process. When once inflammation had ensued he gave a choice of very many preparations for local application. The variety is baffling and would certainly have made it difficult to choose the appropriate substance. Here one can merely mention that they included the boiled leaves of many plants, often mixed with linseed; alum, vinegar, verdigris, turpentine, myrrh and bile. There is one treatment which, in view of later developments, is of some importance, i.e. the use of sea-water. Hippocrates recommended seawater as suitable for cleansing wounds, and added that it has the merit of reducing the swelling. As an example he instanced that the wounds of fishermen did not even suppurate unless one meddled with them. At long intervals since that time sea-water has been commended for the treatment of wounds, and we shall have to consider the modern form of this treatment later.

Advancing another five hundred years, we come to the time of Celsus, who lived in the first century A.D. Celsus stated that the main considerations were to see that the patient did not die from either haemorrhage or inflammation. To stop bleeding the best way (in his opinion) was to apply dry lint over which a sponge wrung out of cold water was applied firmly. If bleeding continued the sponge was soaked in vinegar and re-applied. The cautery was only to be applied as a last resort. The advice is then given-'But if even these are powerless against the profuse bleeding, the vessels which are pouring out blood are to be seized, and round the wounded spot they are to be tied in two places and cut across between. . . . When circumstances do not even admit of this, the vessels can be burnt with red-hot irons.'

The next procedure was to clean the wound. The clots were turned out and the interior of the wound cleansed by a sponge wrung out of vinegar or wine, or even with cold water. When possible the parts were then brought together by stitching or by clips. Strands of twisted wool were used as sutures. When clips were used they were not to be too close together. After closure of the wound no special dressing was recommended for ordinary cases. Celsus comments-'A wound can be treated without foreign or far-fetched medicaments.' However, for those who liked to apply something, he recommended a preparation called 'barbarum', which contained alum, verdigris, litharge, dried pitch, dried pine resin, oil and vinegar. The combined effect of these drugs was probably astringent and slightly antiseptic. A linen bandage was applied over this.

The wound was dressed on the third day and again on the fifth when the extent of the inflammation was estimated. If inflamed, fomentations were applied. If the flesh fungated (i.e. if there were excessive granulations) copper scales or corrosives were applied. 


\section{The Treatment of Wounds through the Ages}

Celsus described the methods of treatment in use at the most flourishing time of the Roman empire, and one must allow that even to modern eyes they were not bad methods. From this time onward there began to mingle with rational methods a considerable amount of much less reasonable practice. Galen's writings do not improve much on Celsus except that he adds torsion of blood vessels as a means of stopping bleeding, and that he mentions the substances of which ligatures were made-linen, silk or catgut.

We meet the first departure from rationality in Oribasius, who wrote (or compiled) at Byzantium in the fourth century A.D. He collected all the medical knowledge available at that time, and thus we gain information about many surgeons whose writings have not come down to us. His account of the treatment of wounds starts well. 'A simple wound being only a division, there is only (need) to bring the divided parts together and apply a circular bandage so that the separated flesh can reunite, without being obliged to do more.' He continues, 'if it be a big wound so that the edges cannot be completely brought together because of accumulation of serum, or if there be pain ... one needs a drying application which will clear away the serum and prevent its re-accumulation. The best application is wine; vinegar and water, or honey and water are also good.' So far, so good, but after this we are given a long list of possible local applications which include crushed snails, which, during the process of crushing, are to be mixed with flour-dust gathered from a wall near to a flour-mill; while another remedy given is to apply earthworms to the wound. The worms were stated to unite divided nerves. Clearly imagination and false analogy had already crept in.

For another thousand years Byzantine practice did not advance much but in the seventh century the rapid rise to power of the Muslim empire led to the development of Arabian medicine and surgery which was primarily based upon texts of the older writers (Hippocrates, Galen, etc.), which had been translated into Arabic. The best known of the Arabian surgical writings are those of Albucasis, who lived in the eleventh century.

In Albucasis we note a preference for the cautery for the stopping of haemorrhage, and the adoption of more complicated local applications. Thus, even for a small uncomplicated wound he recommended local treatment by a special powder of interesting composition. Its ingredients were incense, a red resin known as dragon's blood, and quick or slaked lime; these were mixed together (two parts each of the first two, three parts of the lime), sieved, and applied to the wound.

This powder would certainly have an antiseptic effect and, if put outside the wound, would have protected it from contamination. Unfortunately Albucasis recommended that the wound should be packed firmly with the powder so that the parts would be cauterized before the air could get to them. It is to be feared that this treatment must inevitably have hindered healing and favoured suppuration.

In another place, however, Albucasis recommended the dressing of a wound with lime which had been washed in sweet water and mixed with oil of roses. 


\section{Sir Zachary Cope}

If inflammation supervened he recommended application of oil of roses either by itself or mixed with wine; at a later stage he advised poultices or a digestive ointment.

Western medicine and surgery began its slow upward advance in the twelfth and thirteenth centuries at Salerno in southern Italy and Bologna in northern Italy. Most writers continued to think that suppuration was the normal process of healing. About this time we first come across the use of white of egg as a local application for wounds; it was mixed with oil of roses and with aqua ardenti vini, which must have been some preparation containing alcohol. These preparations were more appropriate than the caustic applications of the Arab surgeons.

About this time occurred the first open rebellion against the view that suppuration in wounds was the normal procedure. A small school arose which taught that, if left alone, wounds might heal without any suppuration. The names of three men need to be remembered-Hugh of Lucca, with whom the idea seems to have originated, Theodoric, Bishop of Cervia (1205-1320), and Henri de Mondeville (1260-1320) who accepted the doctrines and perfected the practice originated by Hugh of Lucca, who unfortunately left no writings of his own.

In the surgical book edited and compiled by Theodoric (translated by Campbell and Colton) the statement on the treatment of simple wounds runs as follows:

In fresh wounds which are full of blood, which exposure to air has not changed, and in which neither any amount of flesh nor of skin has been lost, nothing else is necessary except that their edges should be joined to one another just as they had been naturally, and the compress being soaked in hot wine, let a bandage be skilfully bound round if the flesh bulges.

In another place he writes:

Yet I, trusting to my own experience close all sides of a wound and with dressings (first bathed in wine) placed fittingly on each side and above, and without other medication, I achieve consolidation.

Theodoric was the pupil of Hugh of Lucca and repeatedly gives his master credit for this, at that time, unorthodox method of treatment. In the same way Henri de Mondeville acknowledges the debt he owes to Theodoric for teaching him how to treat wounds. Henri was surgeon to Philip the Fair of France and, as he states, it was partly due to the king's support that he was able to teach his unpopular doctrine. Henri indeed carried the war into his opponent's camp. Listen to his scathing criticism of the orthodox treatment.

At the first dressing the ancients treat wounds in the following manner. If they are small they immediately deepen it, then they insert the little finger forcibly, then the middle and finally the second finger, continually enlarging the wound at the bottom. Then they incise the opening saying that the wound is bigger at the bottom than at the orifice, and that is true, for 


\section{The Treatment of Wounds through the Ages}

they have made it so. All this time the patient wears a sardonic grin. Then if the wound is bleeding they let it bleed until the quantity suffices, for they say that moderate bleeding is good and prevents inflammation. If the wound has bled sufficiently and is still bleeding, they compress it if they can. They dress and treat all wounds by the same method (except fracture of the skull) and fill them with tents soaked in some cold and viscous stuff e.g. white of egg, and over that put pledgets moistened with the same substance. . . . The second dressing is done the second or third day. They take out the tents and refill the wound again with similar tents. Upon that they put suppurative medicaments. ... They continue to treat these wounds with tents and suppuratives for a long time, dressing them 3 times a day in summer and twice in winter.

Henri explains that Theodoric recommended that the wound should be united at once and that, after suture, wine should be applied on pledgets on the outside and not on the inside of the wound. Henri then answers his own rhetorical question. Suppose that the patient says 'Master, I have been to the gates of death and I am therefore fearful. Tell me in what way your modern method is superior to the ancient.' I reply that though both treatments tend to cure it is by different ways. The new method (I) does not probe the wound, (2) does not insert tents, (3) does not lead to suppuration, (4) does not cause a stink, (5) is free from danger, (6) is not painful, (7) is easy to do, (8) allows wine and meat, (9) does not remove bony fragments (skull), (Io) leads to a flat and depressed scar, (II) does not affect the movements of the nerves (tendons).

In other words, Henri contended that quick suture and no meddling led to a quick aseptic healing. The strong opposition which his views encountered is graphically described.

It is dangerous for a surgeon to operate otherwise than as other surgeons. . . . We have proved this for the treatment of wounds according to Theodoric's method. Jean Pitart and I were the first to bring this method to France and to employ it in Paris and in several wars, against the wishes and advice of everyone, particularly the doctors. We have had to put up with the contempt and shameful remarks of the people and of our colleagues the surgeons, full of threats and perils. From some people and doctors every day and at every dressing we have had to put up with arguments and words so violent that, fatigued and half overcome with so much opposition, we have almost given up the treatment, and we should have completely given it up but for the support of his highness the Count of Valois. . . . Moreover we were sustained by the truth; but if we had not been strong in the faith, well regarded by the King, the royal physicians and some scholars, we should have had to abandon the treatment.

This early attempt to introduce the aseptic method of treatment of recent wounds seems soon to have been forgotten.

Theodoric was one of those who praised the virtues of sea-water in the treatment of ulcers, for he writes-'Sea water also tends to cleanse and dry' such ulcers.

The efforts of Theodoric and Henri de Mondeville produced no permanent change. Their methods died with them, and the older techniques continued to be practised for another five hundred years. Guy de Chauliac 


\section{Sir Zachary Cope}

ridiculed the teaching of Henri and Theodore. He wrote in favour of the older methods:

In spite of what some say-that the wound merely as a wound has no need of such treatment - which only occurs rarely and in healthy persons-but where they are, God only knows.

Guy preferred the old suppurative way:

protection of the wound and the prevention of pain and inflammation is achieved by plastering and anointing the part with white of egg and cold substances from the first day. Then with astringent wine; and by openings and counter-openings and putting the limb in suitable position, bleeding and purging when necessary.

For bigger wounds Guy used a mixture of incense, dragon's blood and bol armenica (instead of lime), and he states definitely that the application was not to be put into the wound but over it. So the treatment may not have been so bad after all. Nevertheless most of his teaching was merely a repetition of the views of Albucasis and earlier writers.

In the fourteenth century firearms were invented, and very early it began to be taught that there was some special poison present in gunshot wounds which necessitated unusual treatment. Arabian surgery was generally inclined to use the cautery freely, and it became customary to apply the cautery or scalding oil to such wounds. This method was still in use in the sixteenth century. Everyone knows the story of the way in which Ambrose Paré learned that this was a bad method of treatment. In his writings he has graphically described how after a battle he followed the usual practice of applying to the wounds tents and pledgets dipped in scalding oil of elder mixed with treacle, how he ran out of this dressing and substituted for it a mixture of oil of roses, the yolk of an egg and some turpentine, how next morning he found those who were treated by the old orthodox method were in great pain, while those treated by the improvised mixture were quite comfortable and their wounds were much more healthy-looking. Paré at once gave up the old treatment.

In spite of this sudden conversion on the treatment of gunshot wounds Paré and his compeers had not grasped the principle which had been taught by Theodoric and Henri de Mondeville, and they easily gave credence to the quack who vaunted the merit of an application of which the chief constituents were boiled puppies and earthworms.

In the seventeenth century Richard Wiseman realized that some wounds could heal by first intention, for he commented that 'in small superficial wounds nature of her own accord is wont to effect the cure'. Moreover, he did not approve of any tent or piece of lint being put into the wound as may be gathered from his statement:

Nature has nothing to do here in bringing the lips together, that is the sole work of the surgeon; who must not lay a pledgit or croud a dossil of lint or tent into a little wound, open and make it painful-yet among the pretenders to that art we often meet with such work. 


\section{The Treatment of Wounds through the Ages}

But Wiseman's local application to wounds were still those which had been in use for a thousand years.

In the eighteenth century the man who thought and taught about wounds most wisely was John Hunter. He was critical of the usual methods of treatment, both of the methods of approximation and of the local applications. Four methods of approximation of wound-edges had been in use for two thousand years-by bandage, by various types of suture passed by a needle through the wound-edges, by some form of hook or clip, and by strips of adhesive plaster. For small wounds simple bandaging with a bandage of the roller type was often thought sufficient, and several methods of applying it were taught throughout the Middle Ages. Sutures passed by needle were often used, hooks or clips less often, and plaster strips probably only occasionally. John Hunter taught that wounds could heal by first intention.

A simple wound is such as to admit of union by first intention. In the most simple case of wounds ... the internal parts are left exposed ... and these if not brought into contact with corresponding living parts immediately, or by means of coagulated blood, will inflame and suppurate.

He then enumerates the methods of approximation.

This necessity first suggested the practice of sewing wounds and afterwards gave rise to various inventions in order to answer this end, such as bandages, sticking plasters and ligatures.

He then gives the method he prefers and the reason for so doing.

The interrupted suture which has generally been recommended in large wounds, is still in use, but seldom proves equal to the intention. A piece of sticking plaster, which has been called the dry suture, is more general in its application than the uniting bandage.

Hunter obviously preferred strips of adhesive plaster for bringing together the edges of the wound. $\mathrm{He}$ is severe on the interrupted suture as then practised.

Perhaps the art employed by the surgeon himself may assist in changing the original state of the wound, as the passing of needles and ligatures must always produce suppuration through the whole passage.

Hunter also criticized the common practice of enlarging the entry wound of a missile. He had little faith in local applications. He wrote:

I believe it is not known that we have the power of adding strength to a part by local application; many local applications are recommended to us, respecting many of which I have my doubts.

Hunter pondered over the cause of suppuration. He knew that it could not be due to the gases in the air, for he instanced surgical emphysema which never led to suppuration. He recognized that it followed prolonged exposure and, as 


\section{Sir Zachary Cope}

we have just learnt, he rightly taught that suture material could be an immediate cause of suppuration. But he had no microscope and found no clue to the puzzling changes which so frequently occurred in wounds. No light was thrown on this problem, and no essential alteration in the treatment of wounds occurred until sixty years later when first Pasteur explained the causes of fermentation and putrefaction, and Lister applied that knowledge to prevent those processes in wounds. The teaching of Hunter influenced several generations of surgeons.

It was the genius of Pasteur which led him to prove that fermentation was due to the presence of micro-organisms which were carried on particles of dust floating in the air, which settled on and adhered to solid bodies and freely multiplied in suitable liquids. It was Pasteur who demonstrated that it was possible to destroy or get rid of these micro-organisms either by destroying them by heat, or by filtering them off by substances such as cotton wool. In I863 Pasteur said to the Emperor Napoleon III that all his ambition was 'to arrive at a knowledge of the causes of putrid and contagious diseases', and who in I864 proved to his own and to others' satisfaction that there was no such thing as spontaneous generation. In $186_{5}$ the knowledge of Pasteur's work reached Lister, and at once he thought that it might contain or might lead to the cause of suppuration. It was Lister's happy idea that suppuration in wounds might be due to some of those micro-organisms whose existence Pasteur had proved. It was Lister who first attempted to prevent those invisible and still unidentified organisms from entering wounds and opened the door to modern surgery.

Lister did not use heat to get rid of micro-organisms but relied entirely on antiseptics. He began with crude carbolic acid and applied a dressing soaked in that substance to the wound in a compound fracture with immediate success in preventing suppuration. He soon changed to $I$ in 20 carbolic acid as a dressing and used the same solution (or a weaker one) to sterilize instruments and to purify his hands. He succeeded in his quest of preventing the access of micro-organisms to the wound. He had the same success with both civil accidental wounds and those made by operations, though at that time the wards in which he worked were hotbeds of infection. Those surgeons who followed his teaching implicitly had similar success.

Why then was not surgery and the treatment of wounds immediately revolutionized? Why did surgeons like Lawson Tait, who certainly did not follow the rules laid down by Lister, have such astonishing success? There were several reasons for this. First, Lister relied upon antiseptics alone for protection against the organisms; he neglected the other equally important method of killing microbes, that of heat. It was therefore left to others to demonstrate the value of sterilizing instruments by boiling them in water, of using boiled water as a lotion, and of sterilizing silkworm-gut and silk by boiling. Secondly, many years passed before the guilty micro-organisms were actually demonstrated and seen. Macewen is said to have seen cocci in 1879; it is certain that Ogston demonstrated and named the staphylococcus in 1882 . It would have helped Lister's cause if the organisms could have been identified earlier. Thirdly, Lister, in his 


\section{The Treatment of Wounds through the Ages}

desire for perfection, was continually changing his technique. This constant changing must have been confusing to those who wished to learn and practise his methods, and would certainly discourage those who had but faint interest in the new idea. Fourthly, it unfortunately happened that the part of the body in which the greatest progress was at that time being made-the abdomenwas a part which had considerable natural resistance against infection. So much was this the case that Lister hesitated to advise Keith to adopt the antiseptic method for his operations of ovariotomy. Indeed when Keith considered the adoption of antiseptic methods

Lister at first dissuaded him from doing so, because he recognized that the peritoneal cavity was already provided by nature with special protections against the attacks of micro-organisms (Godlee, p. 287).

Other surgeons who had grasped the principles of the new treatment made use of heat for sterilizing. Thus it came about that asepsis caught up with and even surpassed the Listerian antiseptic system, though antiseptics were still in common use at the turn of the century and are still of the greatest use in certain conditions.

The discovery of the role which micro-organisms played in the production of suppuration enabled surgeons to suture clean wounds with the almost certain prospect of union by first intention. Mildly contaminated wounds, such as those attending compound fracture swith only superficial and mild infection, also usually healed well if the surfaces were washed with antiseptic solution and aseptic or antiseptic conditions were maintained. Badly contaminated wounds, many gunshot wounds, and wounds which had been neglected still suppurated. Nevertheless a heresy had crept into practice and teaching. Many had conceived the idea that antiseptics could purify and sterilize wounds which already had established infection. In the war of $1914^{-18}$ the utter failure of the ordinary antiseptics to stop or even to modify the terrible infections came as a great surprise to the older school of surgeons who had erroneously thought and taught that local antiseptic treatment would prevent or greatly modify the development of sepsis in infected wounds. Lister had never believed or taught this. It was soon proved by laboratory tests, carried out with great skill and ingenuity by Sir Almroth Wright and Mr. (afterwards Sir) Alexander Fleming, that carbolic acid and the other commonly used antiseptics were more likely to do harm than good when applied to wounds in which infection had become established. They also showed that most antiseptics lost their effect in the presence of blood or serum, and that they were unable to penetrate the depths of many gunshot or complicated wounds. Here was a great problem to be solved.

The problem was ultimately solved by investigation along three separate lines of experiment. Sir Almroth Wright and his colleagues tried a physiological approach and applied hypertonic salt solution to the wound; by this means a free flow of serum was induced and this fresh serum exerted a stronger antibacterial action on microbes lying in its path. This method was popular for a time and produced many good results. Another line of research was to 


\section{Sir Zachary Cope}

find an antiseptic which would not damage the tissues and yet would have an antibacterial effect even in the presence of serum; C. H. Browning introduced the flavine compounds which were innocuous to the tissues and could act in the presence of serum, while Carrel found that solutions of the hypochlorites were very beneficial-especially Dakin's solution.

Thirdly, surgeons soon found that excision of damaged tissues reduced the quantity of infection, removed material upon which the remaining microbes might grow, and made the way clear for a more efficacious application of antiseptics. The success of this technique can best be described in the words of Mr. Richard Charles, who played a distinguished part in developing it in France during the First World War.

Surface enlargement of the wound and drainage improved matters a little: removal of foreign bodies and clothing, even more so ... definite conclusions were reached that the only effective method of treatment at the disposal of the surgeon for the primary disinfection of gunshot wounds must be mechanical in nature, and that radical excision of the wound was the correct procedure to adopt. When this was meticulously and adequately carried out within a period of twelve to eighteen hours of injury, the wound for the first time was seen to come under surgical control. The results exceeded all expectations. ... The tremendous success of the pioneer treatment in dealing with soft tissue wounds not only saved thousands of lives, but also justified the application of the procedure to a wound in any part of the body.

The intervention of such a distinguished pathologist as Sir Almroth Wright in the problem of the treatment of wounds was accompanied by a notable medical controversy. At that time Sir William Watson Cheyne was President of the Royal College of Surgeons of England. He had been one of Lord Lister's chief assistants and appeared to hold the view (which was then still widely held) that if a suitable antiseptic were applied in a thorough manner to an infected wound, it should control infection in that wound. He published an article in a surgical journal in which he maintained this view and at the same time he added some critical remarks about laboratory workers who were investigating the problem of wound-treatment. His remarks were taken to be aimed at the work of Sir Almroth Wright and his colleagues. This drew from Sir Almroth a reasoned but very long reply (occupying as many as twenty-two columns of the Lancet) in which he subjected Sir Watson Cheyne's article to very severe criticism.

There are few examples in medical literature of such powerful and destructive logic as are to be found in this article, but it must be confessed that some admirers of Sir Almroth Wright thought at the time that the same purpose could have been effected by a less severe criticism.

At the end of the First World War the recognized method of treatment for a gunshot wound (or for a badly contaminated civil wound) was to excise the damaged and infected tissues, to treat with repeated applications of Dakin's solution until the surface of the wound was bacteriologically relatively aseptic and then to perform secondary suture. Primary suture after excision was usually a failure.

In the interval between the two Great World Wars there took place two 


\section{The Treatment of Wounds through the Ages}

developments of great importance. The first advance was the discovery of the antibacterial effect of the sulphonamide group of drugs. It was in 1935 that Domagk proved the merits of prontosil, and it was not long before a numerous series of drugs-allied chemical compounds-were found to have a similar and in some cases a more powerful effect against a number of micro-organisms, including the septic organisms. The second development was the demonstration by Trueta (during the Spanish Civil War) that many septic wounds of the soft tissues became relatively aseptic when the affected limb or part was completely immobilized in plaster of Paris; this permitted full play for the action of the natural antibacterial action of the bodily tissues.

In the Second World War the method of Trueta did not prove so suitable for there was more mobility of the troops and continued rest could not so easily be attained, but the sulphonamides were found to have a great effect in freeing wounds from bacteria; they could be effective when given systemically or when applied locally.

Alexander Fleming discovered and demonstrated the properties of penicillin in 1929, but it was not till 1943 that, following the work of Florey and Chain, it was proved to be of the utmost value in combating infection by many microorganisms, including the streptococci and the staphylococci. The clinical tests carried out by Sir Howard Florey and the late Sir Hugh Gairns proved the extraordinary effect of penicillin in the treatment of gunshot wounds. At the end of that war the treatment of wounds had become crystallized. Foreign bodies and dead tissue were removed, the margins of the wound-edges were excised, systemic and sometimes local treatment by penicillin was carried out, rest to the part was obtained by an adequate method of splinting, but primary suture was forbidden. Secondary suture was generally done three to five days later. Antitetanic toxoid was used as a prophylactic against tetanus. Allowing for the differences in the type of wound, the same methods are applicable for civilian wounds today.

In one remarkable particular the modern treatment of wounds is the exact opposite to that advised for several thousand years previously-bleeding is never practised. On the contrary in a large percentage of severe wounds the modern surgeon makes good the depleted volume of the patient's blood by a timely and often life-saving blood transfusion.

\section{REFERENCES}

Albucasis, La chirurgie d'Albucase, Traduction française du Dr. L. Leclerc, I86i, p. 197 et seq. Gelsus, De medicina. With an English translation by W. G. Spencer, Loeb Classical Library, 1938, n, 67 et seq.

GODLE E, R., Lord Lister, Oxford, 3rd ed., 1924.

Guy de Ghauliac, La grande chirurgie, E. Nicaise, 1890, p. 206 et seq.

Hip pocrates, Oeuvres complètes, Littré, 1849, vi, 127, I29, 401 et seq.

Hunter, J., Works, edited by J. F. Palmer, 1837, III, 251-60, 542-76. 


\section{Sir Zachary Cope}

LANPRANK, Science of cirurgie, edited by R. von Fleischhacker, Early English Text Society, 1894, p. 33.

Mondeville, H. De, Chirurgie, E. Nicaise, 1893, pp. xvi, 210,21 I, 257.

Oribasius, Oeuvres, Bussemaker and Daremberg, I873, v, 325.

S A B A TI R R, A., Des méthodes antiseptiques chez les anciens et chez les modernes, 1883.

THEODORIC, The surgery of Theodoric. Translated by Eldridge Campbell and James Colton, New York, 1955, pp. 1, 12, 23, 32.

Wiseman, R., Severall chirurgical treatises, 1676, p. 339 et seq.

WRIGHT, A., 'The question as to how septic war wounds should be treated', Lancet, I9I6, II, 503 . 